published as:

Annemarie Mol \& John Law, Embodied Action, Enacted Bodies. The Example of Hypoglycaemia, in: Body \& Society Vol. 10 (2-3): 2004, 43-62

\title{
EMBODIED ACTION, ENACTED BODIES. THE EXAMPLE OF HYPOGLYCAEMIA ${ }^{1}$
}

\author{
Annemarie Mol* and John Law** \\ *Department of Philosophy \\ University of Twente \\ Postbus 217 \\ 7500 AE Enschede \\ The Netherlands \\ email:a.mol@utwente.nl \\ ** Centre for Science Studies and Department of Sociology \\ Lancaster University \\ Lancaster LA1, 4YN, UK \\ email: j.law@lancaster.ac.uk
}

\footnotetext{
${ }^{1}$ Thanks to the people with diabetes and the professionals working with them who were interviewed and/or observed for this study; and especially, in the Netherlands: to 'Miriam T.', Edith ter Braak, Yvonne de la Bije, Willem Erkelens and Harold de Valk; and in the UK to the staff and patients in an anymous general practice in the English North West Regional Health Authority area. Thanks to Claar Parlevliet for her interview work, to Alice Stollmeijer for her analyses of food-issues, to Jeannette Pols, Dick Willems and Ingunn Moser for many discussions on physicalities and subjectivities and to Bernard Kruithof for comments on an earlier version. This earlier version was also discussed at a Body Theory workshop in Paris and we thank all participants, especially Madeleine Akrich, Marc Berg and Pascale Brouet and most of all Lise Kvande.
} 


\section{Summary}

We all know that we have and are our bodies. But might it be possible to leave this common place? In the present article we try to do this by attending to the way we do our bodies. The site where we look for such action is that of handling the hypoglycaemias that sometimes happen to people with diabetes. In this site it appears that the body, active in measuring, feeling and countering hypoglycaemias is not a bounded whole: its boundaries leak. Bits and pieces of the outside get incorporated within the active body; while the centre of some bodily activities is beyond the skin. The body thus enacted is not self-evidently coherent either. There are tensions between the body's organs; between the control under which we put our bodies and the erratic character of their behaviour; and between the various needs and desires single bodies somehow try to combine. Thus to say that a body is a whole, or so we conclude, skips over a lot of work. One does not hang together as a matter of course: keeping oneself together is something the embodied person needs to $d o$. The person who fails to do so dies. 


\section{Living bodies}

We all know this: that the living body is both an object and a subject.

We know that the body is an object of medical knowledge. When it is observed with the naked eye and through microscopes, CT-scans and other visual machinery the body is an object. It is an object when it is measured in a variety of ways, from counting the pulse to determining the blood levels of haemoglobin, creatinin, calcium. And the body-object may be sensed as well: when the hands of the doctor feel for lumps, or for points of orientation in an operation.

The living body is a subject, too. It is us, we: for it is as embodied that we are human beings. So the body is the fleshy condition for, or, better, the fleshy situatedness of, our modes of living. In being a living body we experience pain, hunger or agony as well as satisfaction, ecstasy or pleasure. And while the object-body is exposed and publicly displayed, the subject-body is private and beyond, or before, language.

If one wants to write about living bodies this seems to be the place to start, this given, that we have a public body-object and are a private subject-body. It has been articulated in philosophy, anthropology and sociology as well as in medicine ${ }^{2}$. It appears time and again in testimonies of real life experience. It is what we all know. But maybe it is time to escape from this self-evidence. Maybe it is time to start knowing something else - or in another way.

The body has not always been an object/subject. Michel Foucault suggests that this is a trope that was invented in the early nineteenth century. ${ }^{3}$ Before then, diseases were entities in their own right, classified in nosological tables. Patients seeking relief would describe the ailments they were suffering from, and doctors would then infer which disease was inhabiting the patient's body - and what might next happen. A radical epistemic shift was needed for diseases to become conditions of the human body. After this shift the truth about a disease could no longer be detected by listening to the patients' words. Instead it required a well trained gaze at bodily tissues. Since deviant tissues are usually hidden beneath the skin, sure knowledge about diseases could only be established after death. So the body-object/subject-body distinction with which we now live was established. In the words of Mark Sullivan:

"For Bichat, the medical subject and the medical object were not two different substances within the same individual, but two different individuals: one alive and one dead. Knower and known are epistemologically distinguished with the physician assuming the position of the knower and the patient/corpse the position of the known." ${ }^{4}$

\footnotetext{
${ }^{2}$ A variety of classical texts articulated this (now common) knowledge in a variety of different ways. See for example Merleau-Ponty (1962) for an analysis which mobilises the neurology then current to talk about the subject's body image; or Wittgenstein (1953) for the difficulty of talking about pain and other bodily sensations.

${ }^{3}$ Foucault (1976).

${ }^{4}$ Sullivan (1986), p 344.
} 
Sullivan argues that this split generates the crucial dualism that troubles modern medicine. This is not the dualism attributed to Descartes, between two kinds of substance, body and mind. Instead it is the distinction between substance and activity:

"Here, the activity of self-interpretation or self-knowledge is eliminated from the body rather than the entity of mental substance. The body known and healed by modern medicine is not self-aware." 5

Sullivan and many others seek to integrate people's self-awareness back into modern medicine. ${ }^{6}$ But how? Most authors suggest addition: alongside, or on top of, pathological knowledge of tissues and their deviances, doctors should make space for the self-awareness of their patients. They want medicine not only to look but also to listen; to grant patients their life as well as knowing them as if they were dead.

It may seem hard to disagree with Sullivan's plea for a medicine that attends not only to its patients' organs but also to their self-awareness. But there is a problem with it: it leaves the modes of knowing involved untouched. On the one hand there is an objective, public and scientific way of knowing the body from the outside. On the other hand there is a subjective, private and personal way of knowing the body from the inside. These are the modes of knowing invented in Bichat's time. Foucault describes how the modern epistème (of which they form a part) is linked up with the birth of the clinic. Modern medicine and the gaze at dead and deviant tissues came into being with a specific kind of hospital, a specific system for medical training and a specific set of practices for treatment. Together they gave pathology the last word, while a wide range of techniques (from X-ray to laboratory chemistry) were developed to look beneath the skin of living bodies. And it was only with this way of ordering medical knowledge that the self-awareness of patients was privatised ${ }^{7}$.

Since quite a lot of time has passed since the early nineteenth century we would like to use Foucault's work not as a finished description of 'modernity', but as an inspiration for asking whether we still live within the same modern epistème. We would like to ask about the modes of knowing exhibited in current medical practices, about how the body is currently known. But to put it in this way is already too restrictive because it assumes that it is knowledge that is central. In order to evade this assumption it may be more promising to ask a slightly different question: what is a body in the conditions of possibility at the beginning of the twenty-first century? To phrase it in this way is risky. The danger is that the answer will simply repeat what has already been said by biomedical experts and/or patients: hardly a real contribution. Seeking to add to or correct the knowledge of experts or patients with only the techniques of ethnography

\footnotetext{
${ }^{5}$ idem, p. 344

${ }^{6}$ For a philosophically argued example, see Toombs (1992). And for an example in the mode of social anthropology, see Good (1994). In the literature attention to people's stories about life-events is sometimes given priority over attention to the self-awareness of their bodies. In this text, however, we prefer to not take this way out too quickly, but to respond directly to Sullivan's worry that the body known by modern medicine is not self-aware.

${ }^{7}$ So in good Foucauldian mode we do not take it that feeling oneself from the inside has always had pretty much its present shape, and was 'colonised' and/or displaced by modern medicine. Rather, the two (subjective and objective knowledge) came into being together. For a wonderful study that allows its readers not simply to understand but also to 'feel' how people used to inhabit their bodies differently, see Duden (1991).
} 
at our disposal would be equally futile. No, we don't 'know better'. Asking the question 'what is a body' is worthwhile in quite a different way. It is a way of shifting the grounds on which questions about the reality of bodies may be posed. It moves us to a place where gathering knowledge - whether objective or subjective - is no longer idolized as the most important way of relating to and being in the world.

We all have and are a body. But there is a way out of this dichotomous twosome. As part of our daily practices, we also do (our) bodies. In practice we enact them. If the body we have is the one known by pathologists after our death, while the body we are is the one we know ourselves by being self-aware, then what about the body we do? What can be found out and said about it? Is it possible to inquire into the body we $d o$ ? And what are the consequences if action is privileged over knowledge? In order to explore this we will tell you some stories about hypoglycaemia taken from a continuing study of living with diabetes. ${ }^{8}$

\section{Knowing hypoglycaemia in practice}

So what is hypoglycaemia? This comes from a medical textbook: ${ }^{9}$

'In people without diabetes mellitus plasmaglucose levels vary between 3 and $8 \mathrm{mmol} / \mathrm{l}$, depending on the time that has passed since the last meal. In general the criterion for hypoglycaemia in a patient with diabetes is set at a blood glucose level under $3.5 \mathrm{mmol} / \mathrm{l} .{ }^{10}$

In this definition hypoglycaemia is located beneath the skin and is a characteristic state of a mobile bodily tissue, blood. It is a blood glucose level below $3.5 \mathrm{mmol} / \mathrm{l}$. This, then, is an object-definition in line with the tradition of pathology, portraying a body-we-have. But the textbook locates hypoglycaemia in other places too:

'Hypoglycaemia is a frequently occurring, potentially serious complication in the treatment of diabetes mellitus.' (idem)

The treatment of diabetes mellitus is not located in the body but in hospitals, information leaflets and people's homes. It is in the daily lives of people who suffer

\footnotetext{
${ }^{8}$ For this study we gather and analyse a wide range of 'materials': medical textbooks: scientific journals; patient journals and information leaflets; advertisements; autobiographical texts. We also ethnographically observe clinics for people with diabetes and interview them and the relevant professionals. In the present paper we focus in particular on the treatment for people with diabetes 1 , (early onset diabetes, always making people insulin dependent) which is more difficult to 'manage' than diabetes 2. Diabetes 1 also tends to come with a higher incidence of hypoglycaemia. The quotes in this article are not supposed to tell the reader about the specificities of the people uttering them. Instead they are intended to inform us about practices of dealing with diabetes - practices that are so spread out that they are hard to study ethnographically for a limited number of researchers who have only limited time, and would also prefer not to intrude for long periods into other people's lives by spending days and days with them. So we take professionals as well as people with diabetes as (lay) ethnographers in their own right, taking it upon ourselves to select, translate, combine and contrast their stories.

${ }^{9}$ Treatment practices for diabetes are by no means universal or even general in the 'western world'. In a later stage of our study we hope to introduce international comparisons. Since the field work and interviews mobilised in this article are primarily from the Netherlands, we use a Dutch textbook here. ${ }^{10}$ The reference is from page 142 of van Haeften (1995).
} 
from diabetes mellitus. In daily life hypoglycaemia is something that may occur, happen, be done. It is a potentially serious complication.

It is easy to find sentences like this in medical textbooks and scientific articles: sentences in which phenomena are presented as being part of the practices in which they occur. ${ }^{11}$ But not just anywhere. Practicalities tend to appear in the materials and methods section of papers but not in the conclusions. They tend to appear in clinical presentations but not in epidemiological overviews. Knowledge about a body-we-have and knowledge about a body-we-do tend to alternate. So the shift we are proposing is quite simple even though it has far-reaching consequences. It is to keep the practicalities in the foreground the whole time. Never taking the short-cut of understanding 'hypoglycaemia' as hidden in the body or beneath the skin, our ethnographic description consistently attends to the practices in which it is being done.

So how is hypoglycaemia done? A first important mode is, indeed, by knowing it. Knowing is a practice: it only becomes possible to talk about 'a blood sugar level below $3.5 \mathrm{mmol} / \mathrm{l}$ ' if someone's skin is pricked, a blood sample is taken, and its sugar level is measured. This used to happen in the laboratory. A technician would puncture a vein, collect some blood in a small tube, insert it in a machine and read the outcome. This still happens, but it has been joined by another measurement practice. Since the necessary machinery has been miniaturised, people with diabetes can now carry it round with them and measure their own blood sugar levels. They prick a finger tip and squeeze a drop of blood onto a measurement stick. The stick is put into a slot in the machine and within a few seconds a number is displayed. However, none of this is easy. Pricking the finger may hurt, the number may take some while to appear - and so on. Measurement is demanding and sometimes impossible to handle in practice. Here is an internist in an interview:

'I understand perfectly well it isn't always easy. Like this patient I have who works on the roads. You sit there, in a ditch, dirt all round you, your hands are filthy, nowhere to hide. I wouldn’t measure either, if I were in his position.'

Dirty ditches are a problem. But measuring your blood sugar level is also difficult in a management meeting where you cannot withdraw for a minute or two. Or if you are shopping in town with your friends; or if you are teaching a class of children. Nevertheless, it is possible to measure one's blood sugar level in a clean kitchen or in the bathroom - that is, in a location in which circumstances are as well tamed as in a laboratory. In this way hypoglycaemia may be enacted as a blood sugar level below $3.5 \mathrm{mmol} / \mathrm{l}$.

Sullivan and many other critics argue that medicine should know living bodies in a way that is richer than the knowledge of silenced corpses. It should appreciate that

\footnotetext{
${ }^{11}$ However much those working within the phenomenological tradition stress our 'being-in-the-world' as bodies, they situate (the understanding of) such bodily being beside the representational knowledge of bodies. See e.g. Csordas (1994) Building on the tradition of science studies allows us to include representational practices among other practices. Each is equally mundane. Appreciating the laboratory as a set of practicalities owes most to Latour and Woolgar (1979). Its most beautiful explanation and defence is still to be found in Latour (1988). There are of course also many studies that unravel the practices of daily life. And some, as we are doing here, move from one site to the other. See the essays in Les Objects dans l'action. De la Maison au Laboratoire (1993).
} 
patients are able to act. But asking people with diabetes to be active as laboratory technicians doesn't do the trick: it merely turns them into their own pathologists. It does not do away with the dualism between the knowing doctor and the patient whose body is known but simply shifts this, so that it starts to run right through every individual. Attending not only to the body we have but also the body we are requires knowledge from the inside. And interestingly, in the day-to-day handling (or avoiding) of hypoglycaemia, self-awareness is at least as important as measuring. For if one is sensitive to one's own physical state from the inside, one can feel a hypoglycaemia (a 'hypo') coming on, and do something to increase one's blood sugar level. But being self-aware is not self-evident. It is not something that all people are able to do so long as medicine is not silencing them. Some people are good at it, others are not. As a diabetes nurse puts it:

'Sometimes we have people here who never feel anything. They just do what's on their list. So you try to give them a good list, tell them what to do when, and put some extra measurement moments in. But then when something unexpected happens, they run into problems. While others, well, they tell me they hardly ever measure apart from one or two control days, but they never report any hypos either. They somehow seem to feel it coming.'

The diabetes nurse believes that people who 'somehow seem to feel it coming' are better off because they can lead more flexible lives. They can deal with an unexpected hypoglycaemia that may occur if they have departed from their routines. She enthusiastically describes how she participates in programmes of group instruction where self-awareness is being taught to those who lack it. ${ }^{12}$ In the treatment of people with diabetes, then, self-awareness is not silenced by medicine, but used as a resource - and extended where this is possible. ${ }^{13}$

There may be a dualism between knowing bodies objectively from the outside or subjectively from the inside. But if, as we are suggesting, practice is persistently foregrounded, then it appears that the relation between measuring and 'intro-sensing' hypoglycaemia is more complex. Sometimes, and for some people, feeling bad is enough of a reason to act. Measuring is simply unnecessary. But in other circumstances intro-sensing and measuring are thrown into contrast and the latter is advertised as being more accurate. This is because feeling bad does not necessarily relate to a hypo, but may also be the effect of a drop in blood sugar level from, say, 15 to $8 \mathrm{mmol} / \mathrm{l}$. This means that feeling bad isn't necessarily a reason for increasing one's blood sugar level, but should instead be a reason for measuring it. And some people don't 'feel bad' at all, so they may always have to measure if they want to assess their blood sugar level. But from the ethnographer's point of view the most interesting relation between objectivity and subjectivity comes with the use of measurement machines to train inner sensitivity. In training programmes people are told to guess

\footnotetext{
${ }^{12}$ A possibility which holds most promise for those who have become ill recently: the ability to feel a hypoglycaemia coming on may also deteroriate as a consequence of the diabetes.

${ }^{13}$ Western medicine depends in many respects on the bodily self-awareness of its patients. In order to allow doctors to use their diagnostic tools properly, patients have to first answer questions such as: what do you feel, where does it hurt, at which moments, is it an itching or a knife-like feeling, and so forth. In all the criticism of medicine's neglect of the patient's self-awareness this dependence has been understudied. But see e.g. Strauss et .al. (1985) which pays attention to the articulation work that patients, like doctors, are engaged in.
} 
their blood sugar levels first, before they measure them. The object is not to turn them into accurate number-guessers, but to encourage them to stop whatever they are doing in order to feel their bodies from inside. It is to seduce them into practising selfawareness.

\section{Counteracting, avoiding, producing hypoglycaemia}

But doing hypoglycaemia is not only a matter of knowing it by measuring it from the outside, feeling it from the inside, or some combination of the two. When we asked Miriam T., who has lived with diabetes for years, 'what is hypoglycaemia?' she told a different story:

'Well if at the moment that we diabetics go to sleep we have [a blood sugar of] four [mmol/], then you simply know that at some point you run a risk of getting a hypo in the night, that it's too low. It should be six or seven, but what happens is that, well, oh, shit, I wake up in the middle of the night and shiver, shiver, shiver, and sweat, and then I have to get out of bed and eat something. Not if I'm being well-behaved, but if I'm careless, well, yes, then I have to get out of bed.'

In this story there are numbers (four, six, seven) and there is shivering and sweating. But Miriam T. also talks about getting up in the middle of the night, angry with herself for having been careless. The crucial action required is that of eating.

'And then I scold myself and go to the fridge, I take out the yoghurt and put some sugar in it. And sometimes I sit there on the floor, eating, for that's all I can do at a moment like that, sit on the cold floor of the kitchen and eat my yoghurt with sugar. And then gradually I get better.'

In the daily lives of people with diabetes hypoglycaemia is something they know about, but the point of their dealings with it is not to gather knowledge but to intervene. For Miriam T. the most interesting way of relating to hypoglycaemia is neither to feel nor to measure but to counteract it. So when asked what a hypoglycaemia is, she talks about getting up in the night and eating sugary yoghurt. ${ }^{14}$ Some people even do hypoglycaemia without ever getting to know it at all. They try to avoid it at all costs. As a diabetes nurse reports:

'We also have this patient, an elderly woman who got insulin-dependent recently, who is so afraid of getting a hypo that whenever she feels bad, she eats. So she eats and eats. And she doesn't like to measure her own blood sugar, so she may feel bad, not because her blood sugar is low, but simply because it has just dropped. It was, say, 15 and it dropped to 8 and that makes her feel bad and she wants to avoid having a hypo and she eats - and eats till

\footnotetext{
${ }^{14}$ Eating, in its turn, is linked up with the body in complex ways that obviously go far beyond 'countering hypoglycaemia'. That studying such mundane socio-physical activities may shed new light on a great many aspects of life is shown in the interesting inquiry into the intertwining of food and memory by Sutton (2001).
} 
her sugar is 15 again. And then she’s miserable because, you know, she’s getting fat.'

Being fat is not a 'clinical sign' of hypoglycaemia and yet it may be part of a specific mode of enacting it, that of avoidance. Avoiding hypoglycaemia by eating whenever one feels bad is not a course of action encouraged by nurses. However it is comprehensible, for there are good reasons for avoiding hypoglycaemia. Here's Miriam T again:

'With insulin, after all, you have a lethal drug in the house. People get killed with it. If you shoot up too much and eat nothing, well, then you die.'

In current treatment practices people with diabetes learn to inject their own insulin, but not too much of it. They learn to counteract hypoglycaemia, or, preferably, to prevent it from occurring at all, not by eating whenever they feel bad, but only when this is really necessary. Measuring and feeling form only a small part of all the activities required of 'active patients', and acquiring knowledge is not the aim of these activities. Balancing food intake, exercise, and insulin injections, people with diabetes try, instead, to avoid hypoglycaemias - and hyperglycaemias, too. They must maintain their blood sugar levels at a proper target level.

Medicine has changed these target levels over the last couple of decades. Ideal blood sugar levels are now lower than they used to be, since holding them low tends to postpone the onset of secondary complications. These complications are nasty: as people with diabetes get older they are more likely than others to go blind, to suffer from neuropathy, or to develop atherosclerosis. In clinical trials there have been comparisons between people treated in the traditional way (with a single insulin injection a day and a three-monthly laboratory control measurement of average blood sugar level) and those whose blood sugar levels were tightly regulated at lower levels (maintained with several smaller daily insulin injections and as many selfadministered blood sugar measurements as necessary). The second group turned out to have a better statistical chance of long term health. As one internist says:

'Twelve, fifteen years ago you could still have done a proper trial to investigate whether tight regulation really improves patients' long term outcomes. But now this wouldn't be ethical. You no longer can. Enough proof has been assembled, even though the trials that were done didn't all follow what I think are good treatment programs.'

The current treatment policy is one of tight regulation wherever possible. Statistically this improves people's long term state of health, but it has the disadvantage that it leads to a higher incidence of hypoglycaemia. If target levels are set lower it is not surprising that the frequency of blood sugar levels that are too low increases. Thus, while individuals are taught to avoid hypoglycaemias and to counteract them as quickly as possible, recent clinical trials - and the standards that have followed from them - actively produce hypoglycaemia. This, of course, is not something that has been sought after, but is a negative trade-off of postponing long term complications. It turns out, then, that medical practice is not primarily interested in knowing hypoglycaemia either. In clinical encounters professionals try to increase their 
patients' ability to avoid or counteract hypoglycaemia, while implementing state-ofthe art treatment programmes causes the overall increase in 'hypoglycaemic incidents' - as a side-effect.

\section{$\underline{\text { In- and excorporations }}$}

We asked 'what is hypoglycaemia' and have found that it may be: measured as a blood sugar level below $3.5 \mathrm{mmol} /$; felt as sweating, shivering or an overall sense of discomfort; countered as something that responds to eating sugar; avoided out of fear of coma or, worse, death; while it is also produced as a negative trade-off of postponing long term complications. Done in all these ways, hypoglycaemia is all these things. ${ }^{15}$ But what do they imply for the body? The answer is, two things. First, as they enact hypoglycaemia, bodies do a lot of things: they act. And second, while it is measuring, feeling, countering, avoiding and producing hypoglycaemia the body is being enacted, too. But no, it is more complicated still. For acting and being enacted go together. Thus we may ask: while it is acting, what is a body made to be? This is the question to which we now turn.

Pathologists who observe corpses, or doctors who use instruments in order to see through the skin of a living patient, are primarily concerned with watching. This, at any rate, is the way in which Foucault described the 'clinical gaze', the dominant medical mode of knowing that came into being in the early nineteenth century. The doctor's body is active in the gaze, but only partially. It is primarily the eyes that do the gazing. The technologies that help the physician to 'see through' the skin of living bodies may also address the ears, or the observer's sense of touch or even smell - even if the dominant knowledge-metaphor remains visual ${ }^{16}$. When Sullivan and others ask us to appreciate the self-awareness of the patient they are stressing the importance of another sensory faculty: that of feeling the degree of physical well-being from the inside. Thus the knowledge of bodies involves all the senses ${ }^{17}$. And knowledge-inpractice involves yet more of the body - such as hands that have to manipulate and should not shake too much. Other ways of enacting hypoglycaemia depend not only on the hands, but also on the biting mouth, the digesting intestines and the sugar metabolism of each individual cell. Enacting hypoglycaemia involves the whole body. But this body is not a well defined whole: it is not closed off, but has semi-permeable boundaries.

Let us start with measuring. This certainly depends on the eyes that have to read the display on the measurement machine. But before the eyes the hands have been active. They prick and are pricked. Aim well, next to the fingertip but not in it: if you happen to go blind later in life you will need your fingertips to feel your way round. One hand squeezes a drop of blood out of the other. The hands, too, insert the stick that has

\footnotetext{
${ }^{15}$ For a further exploration of the multiplicity of the objects of medicine that follows from persistently foregrounding practice, with the example of atherosclerosis, see Mol (2002).

${ }^{16}$ All knowledge practices depend on the active body knowing, even if a lot of effort has been spent on expelling the relevance of the body from some of them - notably those knowledge practices called 'science'. About this history, and the persistent and variant relevance of knowing-bodies, see the essays in Lawrence and Shapin (1998).

17 As does other knowledge, that of ethnography included. See, for the latter, Stoller (1989).
} 
absorbed the blood into the slot in the measurement machine. So long as all goes well. The diabetes nurse:

'Sometimes I don't understand industry. Here, try, can you open the cap of this bottle? I can hardly do it myself. And a lot of people with diabetes, when they get older, they have more trouble using their hands. Or, with old people, their hands tremble too much for them to insert a stick into a slot, here, look, this machine here, impossible! Then there are machines around with displays so small that the numbers are hardly readable at all, let alone for someone with bad eyes. But then again, something big and solid that everybody could use, young people don't like that. They want something they can carry everywhere, something small. Fashionably designed, too, so that they can show it off.'

Hands are active in measuring hypoglycaemia but they do not act alone. They interact with machinery. The success of this interaction depends on the extent to which hands and machines are adapted and adaptable to one another. Some things can be done, if only a body is prepared and trained to do them - others falter when a machine is not properly adjusted to the body it must serve. Machines only become instruments if the body can manipulate them and incorporate them in its actions. ${ }^{18}$ So measuring depends on an open rather than an isolated body. The actively measuring body merges with its measurement machines. What about the body that feels? Miriam T., in the middle of the interview:

'Well, excuse me. I've got to go to the kitchen now, I must eat an apple or something.'

Miriam T. feels a hypoglycaemia coming on and fetches an apple - or something - in order to counteract it. She doesn't measure her blood sugar level: she dislikes pricking her finger and avoids doing it if she can. ${ }^{19}$ But neither does her feeling derive from an isolated and well bounded body: it includes a lot more.

'Me, well, I know my body pretty well, and if I were to prick and measure myself right now, I know that I'm fairly low, for I feel kind of, eh, I've got to eat something extra, because I've injected too much. That is, we were having chilli tonight and that's with beans and that's a lot of carbohydrates, and then I tend to inject two or three units more so that it doesn't go up too much, but now I've been doing things in the garden, so, hmm, I have to eat an extra something because otherwise I won't do well. But now we can have nuts in a bit, so I do allow myself that, hah, nuts.'

In her appreciation of a herself as being 'low', Miriam T. includes: carbohydrate tables and her experience with measurement machines; the chilli she has eaten; the

\footnotetext{
${ }^{18}$ As an extenstion of this, it would be interesting to analyse medical technology with the theoretical repertoire that has been developed in anthropology for the study of material culture. See, for instance Arnoldi et.al. (1996),

${ }^{19}$ The question of the amount of pain involved in measurement is interesting in its own right. Some of our informants tell that it doesn't hurt them. One person remarked that it didn’t hurt him because he didn't mind measuring so much - he said he had the impression that the hurt grows with the aversion. However, if one feels no pain at all, this is not a good sign either: it may indicate that neuropathy has set in and is impairing one's sensitivity.
} 
units of insulin she has injected; her gardening; and even the promise of nuts. She incorporates what surrounds her. The self-aware body has semi-permeable boundaries. But not only does what was outside the body come inside, but there is also movement in the other direction. Some bodily activities may take place beyond the surface of the skin. Miriam T.'s husband Josef, for instance, happens to be very good at detecting Miriam T.’s hypoglycaemias:

'Then he looks at me and says 'don't you think you'd better eat something?' Or he doesn't even look, but he gets it from how I'm doing. I get irritated in a particular way, or unfriendly. And he knows where I'm at, what's happening. And usually he’s right.'

Later Josef came into the room and admitted with some pride that he could often feel when Miriam T. was becoming unwell. Indeed, he did not talk about seeing but about feeling it. Thus, while a body-in-practice may incorporate some of its surroundings it may also, how to say this, excorporate some of its actions. The very activity of introsensing may take place outside one's body-proper.

Physical action is needed in measuring and feeling, but also in counteracting hypoglycaemia. To do something about feeling 'low' Miriam T. must bite, chew and swallow. She must do this for herself: no one else can do it for her. But she cannot do it by herself. She needs an apple - or something - to eat. If people are to counteract a hypoglycaemia physically, their surroundings must be prepared for action. Miriam T:

'I never leave the house without food in my bag. Never. Without insulin in my bag, without dextrose in my bag, never. No matter what, I've always got my bag with me. For when I am somewhere, standing somewhere, and have to eat something, well, then I can't have that, that I have nothing with me.'

Miriam takes food whenever she goes somewhere, and has carefully spread dextrose and biscuits around. They are in the glove compartment of her car, in the panniers on her bicycle, in the bedroom upstairs.

'That has become ordinary, it belongs to me. That is me.'

We just put it like this: in addition to one's body, one's surroundings have to be ready for action. But we may also follow Miriam T.'s suggestion: well-prepared surroundings become part of the active self, me, which means that this is far larger than the body.

In enacting hypoglycaemia, bodies act. But these active bodies are not isolated. Instead their boundaries are leaky. They interact and sometimes partially merge with their surroundings. This is even more obvious when measuring and feeling are forgotten, and action comes too late. For if a hypoglycaemia becomes really bad the body begins to lose its capability of acting properly all by itself. With a blood sugar level that is very low one starts to behave strangely, aggressively, as if drunk. Miriam $\mathrm{T}$. has warned her colleagues. 
'So I've said to them, if I'm ever in a state like that, take me out of the main part of the shop, take me out of the shop to the stock room or the office, wherever, the toilets, I don't care, but I would feel embarrassed if I'd been having a good hypo in the shop.'

A severe hypoglycaemia is seriously incapacitating. First the body becomes untrustworthy and embarrassing; later it may slide into a coma. In a coma one cannot eat or drink even if sugar is available. Instead an injection of glucagon is needed: the hormone that leads the body to release part of its store of sugar into the bloodstream. A comatose body can still respond to glucagon, but someone else needs to do the injecting. Josef and a few of Miriam T's colleagues in the supermarket have learned how to do this. If her hands and mouth are no longer able to act it is they who must counteract her hypoglycaemias. Here again, then, as with measuring and feeling, the boundaries of the body-in-practice are partially permeable. An active body incorporates bits and pieces of the world around it, while its action may be shifted out of the body, excorporated.

Persistently foregrounding practice changes our appreciation of the body, the body-inaction. Observing eyes are still important (they must read the numbers on the display of the measurement machine) but they are joined by manipulating hands (which prick and squeeze out blood, or carry sugar to the mouth). Intro-sensing remains important, but eating and drinking appear to be even more crucial to survival. Indeed, the paradigmatic activity of the body-in-action is not observation, but metabolisation. This suggestion fits well with our earlier observation that the active body has semipermeable boundaries. An observing body does not: it sees what is outside, and feels what is within. Our eyes look around, while one of the crucial steps in acquiring selfawareness is the ability to differentiate between self and other, between who one is from the inside and what, being outside it, one is not. ${ }^{20}$ However, for the metabolic body, inside and outside are not so stable. Metabolism, after all, is about eating, drinking and breathing; about defecating, urinating and sweating. For a metabolic body incorporation and excorporation are essential.

\section{$\underline{\text { Non/coherences }}$}

The body is actively engaged in enacting hypoglycaemia; (the threat of) hypoglycaemia, in its turn, helps to enact the body - in a quite specific way. There are many different ways of enacting bodies ${ }^{21}$. For instance, living with asthma makes people acutely aware of the air they breathe, as does practising yoga. ${ }^{22}$ People who have gone blind later in life have given gripping descriptions of the opaque, obstacleridden space they have come to inhabit. ${ }^{23}$ Trans-sexuality comes with an overwhelming sense of living in a sexed body with genitals that are either

\footnotetext{
${ }^{20}$ See for an experimental investigation into the way difference between self and other is established in people bodily awareness early in life: Butterworth (1995).

${ }^{21}$ This may, with a slightly different twist, also be called 'performing bodies'. For a defence of the 'performative turn' in the language of philosophy, with the many ways of doing differences between the sexes as its target, see Butler (1993).

${ }^{22}$ For asthma, see Willems (1998).

${ }^{23}$ See, for instance, Golledge (1997).
} 
inappropriate or desirable. ${ }^{24}$ The gym may produce strong muscles or give one a sense of their inadequacy. Those who try to lose weight come to inhabit a metabolic reality in which food consists of calories, and physical exercise is a way to lose these. And, returning to the day-to-day reality of living with diabetes, here the body is also enacted as a metabolic system, though now appreciating food is matter of calculating carbohydrates and doing exercise a way of burning sugar. What is primarily at stake is short term sugar balance rather than long term accumulation of body fat.

In the metabolic system relevant to living with diabetes many things are linked together: food with insulin with exercise with blood sugar level. Blood sugar level, in its turn, has yet more physical links, since over time high blood sugars cause arterial obstruction by atherosclerosis, a deterioration of eyesight, and a loss of sensitivity due to degradation of the neurons. The body is entangled in ever so many ways with the diabetes it lives with. And yet it is not a coherent whole. Instead, it is a set of tensions. For instance, there are tensions between the interests of its various organs. Regulating blood sugar tightly may be good for the arteries, the eyes and the neurons, but since it increases the risk of hypoglycaemia, it is bad for the brain. Internist:

'Let me tell you, it worries me, it does. Since these trials have been published tight regulation has become too popular. My younger colleagues tend to go for it, just like that, without wondering if people are really up to it, if they can stay low without sliding into too many hypos. It is in the literature, it is 'science based'! The less experience doctors have the more they love the 'science based'. But we've started to ask patients a bit more systematically about their hypoglycaemic incidents, making them keep diaries and stuff, and the numbers they report are shocking, a lot higher than we estimated. And I've looked into the literature a bit, for gradually there's more research into hypoglycaemia of course, and there is one report after another about hypos causing brain damage. Nobody knows just yet how much brain damage.'

Tight regulation is not good or bad for the body as a whole. It is good for some parts of the body and bad for others. Thus there are tensions, in both the body and people's daily lives. What is the least bad option? To allow a higher blood sugar level and risk atherosclerosis, blindness, or lack of neuronal sensitivity in twenty years? Or to hold it lower, but to risk hypoglycaemias that straight away mean that it is dangerous to drive or carry children because of the possibility of coma? Which life to live, and which body? One that loses count and has shaking hands but can feel? Or one with clogged arteries that has gone blind and can't feel too well, but at least is clearheaded? Such are the options which confront people with diabetes. ${ }^{25}$

But no, it is misleading to talk about options. For if one had a choice it would be obvious what to opt for: an ideally balanced combination. Tight regulation, a low blood sugar level, and the quick detecting and countering of hypoglycaemias. This ideal however, is unsustainable. It depends on the ability to assess one's blood sugar level, calculate what one eats, and keep track of the energy one uses up in exercise unremittingly, moment by moment, without ever stopping. But there is more. The

\footnotetext{
${ }^{24}$ For an exploration of the sexed body illustrated with the example of transsexuality, see Hirschauer (1993).

${ }^{25}$ For a further exploration of the coexistence of various norms in medicine, see Mol (1998).
} 
most tantalising feature of trying to maintain a stable blood sugar balance is that one may still fail however hard one tries. Sometimes blood sugars simply behave in unpredictable ways. Miriam T.:

'You never know what's done it. Emotions are typically hard to deal with, very much so. They may be energy spenders, paff, there you go, a bit of laughing or crying, and you have a low. But then again: they may also lead to the release of whatever sugar you store. Then when I do a measurement I think: I didn't eat anything for hours. So why is it thirteen, thirteen?'

Sugar balance is part of a metabolic system: the term suggests a closed circuit, but some variables are always missing. They behave unpredictably or they are not known. This means that the obligation of constant control implies the threat of unexpected failure. And you never know what's done it. The same is true for long term complications. Low blood sugar targets are intended to prevent secondary complications, but even those who follow a tight regime may still fall victim to them. Internist:

'And then people say to me, they say: 'Oh, doctor, I saw this person in the waiting room, and one of his legs had been amputated. That scares me, it scares the hell out of me. Now if I do my self-controls properly, and stay below ten as I should, please promise me that it won't happen to me, that I'll have to have a leg amputated.' That's what they want to be reassured about. But of course I can't promise anything. I wish I could, but I can’t.'

Statistically the correlations are clear: tightly regulated blood sugar balances lead to fewer complications later in life than blood sugar levels that are high or jump up and down. But what happens to individuals is unpredictable. Eyes go blind, or they do not. The development of neuropathy may be postponed, or not. Atherosclerosis may develop quickly, or not - and if it develops quickly the leg arteries may deteriorate so much that amputation is the only way to stop pain, or prevent gangrene and death. This, then, is a second tension that plagues the body living with diabetes: the tension between control and capriciousness. However many calculations one makes, one's blood sugar level will still behave erratically. However successfully one's life may be under control it still throws up distressing surprises. Modern diabetes treatment demands that patients consistently keep accounts of everything about their bodies, even if it appears in the process that those bodies cannot be counted on.

A third tension arises from the way in which a variety of necessities and aspirations have to be held together and embodied, as we might put it, 'single-bodiedly'. The body-with-diabetes comes with a set of tensions, but people with diabetes are not only 'people with diabetes'. They may have asthma, do yoga, be blind or transsexual, go to the gym, or try to lose weight. They may work in ditches, at board meetings, or in front of class rooms. They may fall in love or out of it, have depressions or attacks of flu, go on holiday, work in the garden, go shopping or take exams. The specificities of the other ways in which people live their bodies somehow have to be combined with those to do with diabetes. 
Cecilia H.: 'I was a real sports person. I loved to run, swim, cycle, play volleyball, tennis, lots of things. So that is what I was most concerned about when I heard about my diagnosis, that I would have to give up that part of me. And at first, indeed, I felt so miserable I thought I'd feel weak as water for the rest of my life. But then gradually I've conquered it, got it back, sport, quite a lot of it really. I simply wanted it. I wanted it so much. And I did it. But it wasn't easy, it still isn't. For the point is: you may get a hypo when your muscles use up so much energy, not just then and there, immediately, but even hours and hours later. So if you run in the afternoon, you risk a hypo in the night.'

The body of the sports-person and the body of the person-with-diabetes are in tension. The bursts of energy of the former do not co-exist very well with the precarious energy balance of the latter. This is a difficult tension. Some people successfully manage the ceaseless business of juggling it, and live with it for a long time. Those who cannot do this have to give up 'a part of themselves'. If dealing with hypos that come in the night is too complicated, they may give up being a sports person. But if they stick to sport and test the limits then there is the risk that one day they fall over the edge and die. ${ }^{26}$ What this suggests is that the assumption that we have a coherent body or are a whole hides a lot of work. This is work someone has to do. You do not have, you are not, a body-that-hangs-together, naturally, all by itself. Keeping yourself whole is one the tasks of life. It is not given but must be achieved, both beneath the skin and beyond, in practice.

\section{What follows}

In the Western theoretical tradition 'the body' is characteristically evoked as the exemplary case of what it is to be whole. An 'organic whole' may even sound like a tautology. ${ }^{27}$ This fits with knowing the body as something we have and something we are. The body-we-have, awaiting the gaze of the observer on the examination table, does not extend beyond the edges of the table. It stays passively within its skin. The observer's task is to understand how it hangs together: the systematic coherence of the body-we-have is never questioned. But the body-we-are is also, or should be, a whole. People whose body-images are not coherent, who do not feel their bodies to be integrated, are diagnosed as deviant. And modern medicine, with its plurality of specialisms, is widely criticised for failing to appreciate our wholeness. If we are a whole, or so the criticism goes, why are we not treated accordingly?

\footnotetext{
${ }^{26}$ Indeed one of the internists observed and interviewed described a patient of hers who does not want to give up rally diving - a sport that is seriously dangerous for someone with diabetes, because if you get into a hypo it is impossible for others to get you out of it. Somehow living on the edge may, for some people, be too worthwhile to give up. See on the combination of risky sports and disabilities see Moser (2003).

${ }^{27}$ In their great attack on the way 'Western thought' tries to forget about 'the body', Lakoff and Johnson explore many fascinating body-related metaphors, that of 'organic wholeness' among them. But while they bring the body inside philosophy that has for so long sought to exclude it, it is still as a body we have and are. Their 'body' remains observational, it is not a body we $d o$, and it is not metabologic. See their (1999).
} 
However, if we foreground the practices for dealing with reality and do so persistently, the body's 'organic wholeness' is no longer self-evident. But this does not imply that the body we do is fragmented, the converse of being whole. If we were to do our bodies in ways that fragmented them, death would quickly follow. The body we $d o$ is neither a whole, nor fragmented. Instead it has a complex configuration. ${ }^{28}$ There are boundaries around the body we do: it is Miriam T. who shivers when she has a hypo in the night and not Joseph, her husband. But these boundaries are semipermeable: Joseph may feel Miriam T.'s hypo for her, and the sweet yoghurt she eats stops her hypo. So long as it does not disintegrate, the body-we-do hangs together. It is, however, full of tensions. There are tensions between the interests of its various organs. Tensions between taking control and being erratic. Tensions, too, between the exigencies of dealing with diabetes and other demands and desires. In the day-to-day practice of doing bodies such tensions cannot be avoided. Like it or not, they must simply be handled.

The body-we-do is not a whole. Keeping ourselves together is one of the tasks of life. This has implications for what one might ask or expect of medicine. Sullivan suggested that medicine should add its patients' self-awareness to the results of its own pathological gaze. Our suggestion is different. It is that instead of adding a further layer of knowledge, medicine should shift its self-understanding. Medicine should come to recognize persistently that what it has to offer is not a knowledge of isolated bodies, but a range of diagnostic and therapeutic interventions into lived bodies, and thus into people's daily lives. Even the pathological gaze is not merely a gaze, but involves manipulation. Medicine's activities always concern both what is beneath and what is beyond the skin. But if all medical operations, even if they simply seem to address bodies, are interventions in lives, then they should be appreciated accordingly. Thus not only their effectiveness in improving one or two parameters, but the broad range of their effects deserves self-reflexive attention. ${ }^{29}$ Not all of these effects should be expected to be for the better. In articulating how it is doing, in considering the effects of its activities, medicine would be wise to confront its own tragic character: medical interventions hardly ever bring pure improvement, plus a few unfortunate 'side-effects'; instead they introduce a shifting set of tensions.

Putting it in this way, we may seem to suggest that medicine's self-reflections should take an ethnographic turn. And so we do ${ }^{30}$. Interestingly, ethnographic methods that foreground practices and draw together disparate entities in a single story aren't new to medicine. In the materials and methods section of research articles practicalities of all kinds (the setting of the intervention in question, the technology mobilised, patient characteristics, and so on) are scrupulously made explicit. It is only in the conclusion that they tend to be forgotten. And listen to the clinical interview: a doctor asks how are you? or what can I do for you? and expects the patient to tell a story about dailylife events in which entities of all kinds (beans, blood, table companions, cars, needles,

\footnotetext{
${ }^{28}$ For a variety of explorations of complexity see the contributions to Law and Mol (2002).

${ }^{29}$ This implies that clinical epidemiology is no longer sufficient for the evaluation of medical interventions. For an example that shows how exploring the details of clinical interventions and their various effects may help to not just evaluate but even improve the clinic, see Lettinga and Mol (1999). ${ }^{30}$ A self-understanding in which medicine is appreciated as a set of techniques enacting bodies also helps elsewhere, e.g. to understand the deep divergence between, as well as the possible coexistence of, different medical traditions - such as the 'Western' and the 'Chinese' tradition. For this see Kuriyama (1999).
} 
sugar) coexist and interfere with one another. A good case history, finally, tells about a patient's situation in a language that moves from blood sugar levels to work ambitions to the doses of insulin prescribed to love life to previous operations to saturated fat uptake to temper and if need be back again. Why not tell stories about medicine in a similar way?

Medicine's current self-reflection is predominantly epidemiological in character. Epidemiology brings together disparate entities too, but its method of accounting isolates every so-called variable from all the others and is incapable of articulating links and tensions between them. At this point ethnographic recounting is a more promising technique: it can produce rich stories of lived bodies in which medicine figures as a part of daily life. But smooth narratives that seek to bring coherence will miss the point. If the tragic aspects of living-in-tension and intervening-for-the-best are to be described, jagged story-lines are needed. And they should be told by a variety of narrators whose voices may be drawn together and/or clash. For this is where patients come in again: aware, not just self-aware, but equally able to tell stories about medicine and the effects of its interventions. ${ }^{31}$ The overall aim of a multi-voiced form of investigative story telling need not necessarily be to come to a conclusion. Its strength might very well be in the way it opens questions up.

No, if medicine were to never forget about practicalities again, if it were to attend persistently to the body-we-do, this would not solve all its problems, let alone all problems that plague us, its patients. But even so, it is worth a try.

\footnotetext{
${ }^{31}$ So far it has mainly been patients who have told stories about their lives with medical interventions together with disease. Other possble participants have been much less forthcoming. One might say that what we argue for here is that the turn to practice that such literature exemplifies, be taken up in professional self-reflection as well. (See e.g. Frank (1995), Murphy (1990), and, for an intriguing mixture of daily life stories and a cultural analysis, Stacey (1997))
} 
$\underline{\text { References }}$

Arnoldi, Mary Jo, Christraud Geary, and Kris Hardin (eds) (1996),

African Material Culture, Bloomington: Indiana University Press.

Butler, Judith (1993),

Bodies that Matter: on the Discursive Limits of "Sex", New York and London:

Routledge.

Butterworth, G. (1995),

'An Ecological Perspective on the Origins of Self', pages 87-106 in José Luis

Bermúdez, Anthony Marcel, and Naomi Eilan (eds), The Body and the Self,

Cambridge, Mass.: MIT Press.

Duden, Barbara (1991),

The Woman Beneath the Skin: a Doctor's Patients in Eighteenth Century Germany, translated by Thomas Dunlop, Cambridge, Mass: Harvard University Press.

Csordas, Thomas (ed) (1994)

Embodiment and Experience. The Existential Ground of Culture and Self, Cambridge:

Cambridge University Press.

Foucault, Michel (1976),

The Birth of the Clinic: an Archaeology of Medical Perception, London: Tavistock.

Frank, Arthur (1995),

The Wounded Storyteller: Body, Illness and Ethics, Chicago and London: The

University of Chicago Press.

Golledge, Reginald G. (1997),

'On Reassembling One's Life: Overcoming Disability in the Academic Environment', Environment and Planning D: Society and Space, 15: 391-409.

Good, Byron J. (1994),

Medicine, Rationality and Experience: an Anthropological Perspective, Cambridge:

Cambridge University Press.

Hirschauer, Stefan (1993),

Die soziale Konstruktion der Transsexualität: über die Medizin und den

Geschlechtswechsel, Frankfurt: Suhrkam.

Kuriyama, Shigehisa (1999),

The Expressiveness of the Body and the Divergence of Greek and Chinese Medicine,

New York: Zone Books.

Lakoff, George, and Mark Johnson (1999),

Philosophy of in the Flesh: The Embodied Mind and its Challenge to Western

Thought, New York: Basic Books. 
Latour, Bruno (1988),

The Pasteurization of France, Cambridge Mass.: Harvard.

Latour, Bruno, and Steve Woolgar (1979),

Laboratory Life: the Social Construction of Scientific Facts, Beverly Hills and

London: Sage.

Law, John, and Annemarie Mol (eds) (2002),

Complexities: Social Studies of Knowledge Practices, Durham, N. Ca.: Duke

University Press.

Lawrence, Christopher, and Steven Shapin (eds) (1998),

Science Incarnate: Historical Embodiments of Natural Knowledge, Chicago and

London: Chicago University Press.

Les Objects dans l'action. De la Maison au Laboratoire (1993),

Raison Pratique, 4, Numéro special, Paris.

Lettinga, Ant, and Annemarie Mol (1999),

'Clinical Specificity and the Non-Generalities of Science. On Innovation Strategies for

Neurological Physical Therapy', Theoretical Medicine and Bioethics, 20: 517-535.

Merleau-Ponty, Maurice (1962),

Phenomenology of Perception, translated by Colin Smith, London: Routledge \&

Kegan Paul.

Mol, Annemarie (1998),

'Lived Reality and the Multiplicity of Norms: a Critical Tribute to George

Canguilhem', Economy and Society, 27: 274-284.

Mol, Annemarie (2002),

The Body Multiple: Ontology in Medical Practice, Durham, N. Ca., and London:

Duke University Press.

Moser, Ingunn (2003),

'Living After Traffic Accidents: On the Ordering of Disabled Bodies', PhD, University of Oslo.

Murphy, Robert (1990)

The Body Silent, New York and London: W.W. Norton.

Stacey, Jackie (1997)

Teratologies. A Cultural Study of Cancer London and New York: Routledge.

Stoller, Paul (1989),

The Taste of Ethnographic Things: the Senses in Anthropology, Philadelphia:

University of Pennsylvania Press.

Strauss, Anselm et.al. (1985), 
Social Organisation of Medical Work, Chicago and London: University of Chicago Press.

Sullivan, Mark (1986),

'In what sense is contemporary medicine dualistic?' Culture, Medicine and Psychiatry, 10: 331-350.

Sutton, David (2001),

Remembrance of Repasts. And Anthropology of Food and Memory, Oxford/New

York: Berg.

Toombs, S. Kay (1992),

The Meaning of Illness: a Phenomenological Account of the Different Perspectives of Physician and Patient, Dordrecht: Kluwer.

van Haeften, T.W. (1995),

'Acute complicaties - hypoglykemische ontregeling', in E. van Ballegooie and R.J. Heine (eds), Diabetes Mellitus, Utrecht: Bunge.

Willems, Dick (1998),

'Inhaling Drugs and Making Worlds: a Proliferation of Lungs and Asthmas', pages 105-118 in Marc Berg and Annemarie Mol (eds), Differences in Medicine.

Unravelling Practices, Techniques and Bodies, Durham, N.Ca. and London: Duke University Press.

Wittgenstein, Ludwig (1953),

Philosophical Investigations, Oxford: Blackwell. 